Research Article

\title{
Effect of Nanosilica on the Fresh Properties of Cement-Based Grouting Material in the Portland-Sulphoaluminate Composite System
}

\author{
Shengli Li and Tingting Xu \\ School of Civil Engineering, Zhengzhou University, Zhengzhou 450001, China \\ Correspondence should be addressed to Shengli Li; 1sl2009@126.com
}

Received 24 April 2016; Revised 11 August 2016; Accepted 30 August 2016

Academic Editor: Chunhui Yang

Copyright @ $2016 \mathrm{~S}$. Li and T. Xu. This is an open access article distributed under the Creative Commons Attribution License, which permits unrestricted use, distribution, and reproduction in any medium, provided the original work is properly cited.

\begin{abstract}
The effect of NS particle size and content on the fresh properties of the grouting material based on the portland-sulphoaluminate composite system was analyzed. The experimental results indicated that air content increased and apparent density decreased, with increased NS content, but the NS particle sizes have minimal effect on the air content and apparent density. The setting time of mortar was significantly shortened, with increased NS content; however, NS particle sizes had little influence on the setting time. The effect of fluidity on the mortars adding NS with particle size of $30 \mathrm{~nm}$ is larger than NS with particle sizes of 15 and $50 \mathrm{~nm}$ and the fluidity decreased with increased NS content, but the fluidity of mortars with the particle sizes of 15 and $50 \mathrm{~nm}$ is almost not affected by the NS content. XRD analysis shows that the formation of ettringite was promoted and the process of hydration reaction of cement was accelerated with the addition of NS. At the microscopic level, the interfacial transition zone (ITZ) of the grouting material became denser and the formation of C-S-H gel was promoted after adding NS.
\end{abstract}

\section{Introduction}

Nanomaterials are attracting increased attention in many fields [1]. When ultrafine particles are mixed into cement paste, mortar or materials with different characteristics from conventional materials were obtained [2-4]. The properties of cement-based grouting materials heavily rely on the properties of nanoscale solid particles, for example, particles of calcium-silicate-hydrates (C-S-H), or nanosized holes at the interfacial transition zone between cementitious material and aggregate particles [5]. The typical characteristics brought about by nanoscale particles or voids are strength, durability, and volume stability [6]. Nanoparticles of silica $\left(\mathrm{SiO}_{2}\right)$ or nanosilica (NS) can fill the voids between particles of C-S$\mathrm{H}$ gel, demonstrating interstitial filling. Furthermore, as the pozzolanic reaction with $\mathrm{Ca}(\mathrm{OH})_{2}$, the amount of C-S-H gel increases and leads to increased compacting formation [1].

Previous research has indicated that nanoparticles can improve fresh and hardened state properties [3, 7-12]. Amorphous silica can significantly affects $\mathrm{C}_{3} \mathrm{~S}$ hydration [7]. NS shortened the setting time of mortar when compared with silica fume (SF) and reduced bleeding water and segregation; moreover, it also can improve the cohesiveness force of the cement-based grouting materials $[8,9]$. When mixed with superfine fly ash, properties of the cement-based grouting materials better than those gained by the use of silica fume alone are guaranteed [3]. Moreover, the compressive strength of mortar with SF is enhanced compared with formulations without other additions [10-12]. The smaller size of NS particles permits them to function as filler by occupying spaces in the cement composites, thereby reducing porosity and reinforcing mechanical performance. Some researchers suggested that the optimal dosage of NS has to be small ( $1 \mathrm{wt} \%-5 \mathrm{wt} \%)$ because of the agglomeration caused by difficulties in the dispersal of particles during stirring. On the contrary, others declared that the improvement of the performance can also be obtained with higher dosages of approximately $10 \mathrm{wt} \%$; if appropriate adjustments are made to the formulation to avoid excessive self-constriction and microcracking, which could prevent the strength from growth $[8,10-13]$.

The sizes and properties of NS, which are similar to SF, have been studied as a potential mineral admixture for 


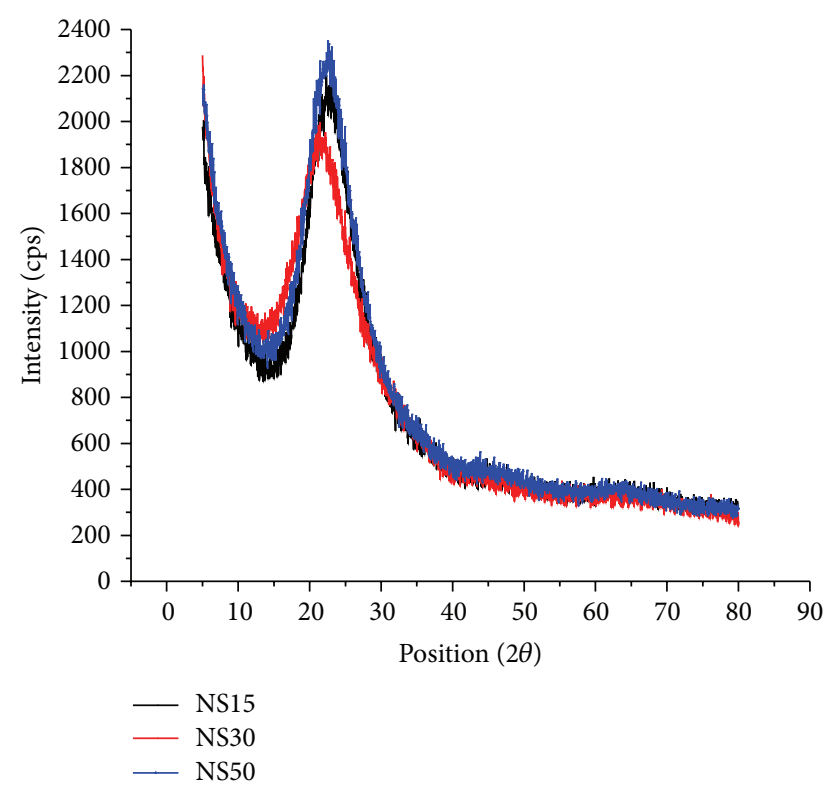

FIGURE 1: XRD analysis of NS materials.

cement pastes $[2,11-14]$. Nevertheless, NS can also reveal additional features, such as reducing the setting time, changing the rheological property, and changing physical performance of portland cement pastes [8,15-21]. The addition of nanoscale silica into the cement-based grouting materials is confirmed to be beneficial to civil engineering [22]. The use of NS has been studied in various fields with several types of materials [23-28].

Previous studies only include the cement grouting materials with the ordinary portland cement and only one size of NS. In this paper, three types of particle sizes of NS mixed with the cement-based grouting materials of portlandsulphoaluminate composite system were analyzed. This paper reports the effects of nanosilica on rheological properties, setting time, air content, and apparent density of cementbased grouting material in the portland-sulphoaluminate composite system. The phase determination (XRD and SEM) of cement pastes was also investigated.

\section{Experimental Programs}

2.1. Materials. The chemical composition of the materials in this work was investigated by X-ray fluoroscopy (XRF), Xray diffraction (XRD), and transmission electron microscope (TEM). The chemical composition of the portland cement and sulphoaluminate cement is shown in Table 1. The NS material used in this work was provided by Hangzhou Wanjing New Material Co., Ltd. Three types of NS, namely, NS15, NS30, and NS50, were employed. The chemical composition of NS is shown in Table 2. The XRD of the NS materials was performed in a PANalytical X'Pert PRO MPD with a $2 \theta$ range of $4.983^{\circ}-79.983^{\circ}$ and a step of $0.033^{\circ}$. The XRD patterns of NS are shown in Figure 1. The intensity peaks were associated to $2 \theta$ angles of $22^{\circ}, 21^{\circ}$, and $23^{\circ}$ for NS15, NS30, and NS50, respectively. Figure 2 shows a TEM image of NS,

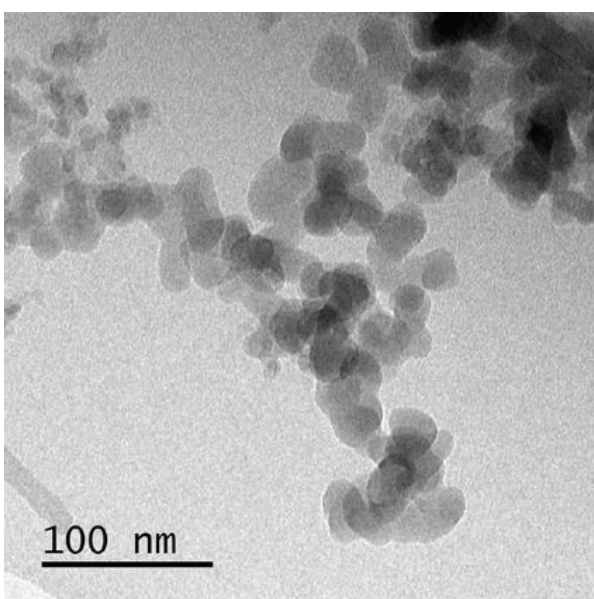

Figure 2: TEM image of NS30.

TABLE 1: Chemical composition of ordinary portland cement and sulphoaluminate cement.

\begin{tabular}{lcc}
\hline \multirow{2}{*}{ Item } & \multicolumn{2}{c}{ Chemical composition (\%) } \\
& P.O42.5 & R.SAC42.5 \\
\hline $\mathrm{SiO}_{2}$ & 15.80 & 4.23 \\
$\mathrm{Al}_{2} \mathrm{O}_{3}$ & 5.47 & 11.60 \\
$\mathrm{Fe}_{2} \mathrm{O}_{3}$ & 2.72 & 0.97 \\
$\mathrm{CaO}$ & 48.00 & 42.96 \\
$\mathrm{MgO}$ & 2.13 & 2.34 \\
$\mathrm{SO}_{3}$ & 1.59 & 13.58 \\
\hline
\end{tabular}

P.O42.5: ordinary portland cement 42.5 .

R.SAC42.5: sulphoaluminate cement 42.5 .

TABLE 2: Chemical composition of NS.

\begin{tabular}{lccc}
\hline \multirow{2}{*}{ Item } & \multicolumn{3}{c}{ Chemical composition (\%) } \\
& $\mathrm{NS} 15$ & $\mathrm{NS30}$ & NS50 \\
\hline $\mathrm{SiO}_{2}$ & 66.79 & 79.10 & 68.26 \\
\hline
\end{tabular}

NS **: NS particle size of $* * \mathrm{~nm}$.

thereby confirming that the silica was a nanomaterial. China ISO standard sand was used in this test and the parameter of ISO standard sand was shown in Table 3. The superplasticizer (SP) is a polycarboxylate high-range, water-reducing agent with $\mathrm{pH}=6-8$ and $40 \%$ solid content in powder form. In addition, the SP used in the experiments was produced by Jinan Sunny Chemical Science and Technology Co., Ltd. The chloride ion content was less than $0.03 \%$. Tap water from the laboratory was used in the work.

2.2. Paste and Mortar Mixing Process. Fresh mortars were prepared with binder/aggregate weight ratio (B/A) of $1: 2$ and water/binder $(\mathrm{W} / \mathrm{B})$ ratio of 0.35 . Mortars were produced with $0 \%-5 \%$ NS in weight, replacing cement. The mixing compositions of mortars are listed in Table 4 . The effects of different particle size of NS on the grouting materials also were studied with NS content $1.5 \mathrm{wt} \%$ in Table 4 . The preparation of mortars involved (a) weighing the components, (b) 
TABLE 3: Particle size distributions of ISO standard sand.

\begin{tabular}{lc}
\hline Side length of the square hole $(\mathrm{mm})$ & Sieve residue $(\%)$ \\
\hline 2.0 & 0 \\
1.6 & $7 \pm 5$ \\
1.0 & $33 \pm 5$ \\
0.5 & $67 \pm 5$ \\
0.16 & $87 \pm 5$ \\
0.08 & $99 \pm 5$ \\
\hline
\end{tabular}

adding NS and SP into water with a glass, mixing them at high speed to form an aqueous suspension, and (c) pouring the solid components into water and mechanical mixing. During the mixing process, the stirring blade of the mortar mixer was rotation and revolution, and the mortar mixer blended mixture at a constant low speed (at the rotation speed of $140 \mathrm{r} / \mathrm{min}$ and at the revolution speed of $62 \mathrm{r} / \mathrm{min}$ ) for $30 \mathrm{~s}$. Next, the mortar mixer blended mixture at the same low speed for another $30 \mathrm{~s}$ and the sand was added into the mixing pot at the same time. Then, the mortar mixer blended mixture at a constant high speed (at the rotation speed of $285 \mathrm{r} / \mathrm{min}$ and at the revolution speed of $125 \mathrm{r} / \mathrm{min}$ ) for $30 \mathrm{~s}$ and the mortar mixer stopped stirring for 90 s subsequently. Finally, the mortar mixer blended mixture at a constant high speed (at the rotation speed of $285 \mathrm{r} / \mathrm{min}$ and at the revolution speed of $125 \mathrm{r} / \mathrm{min}$ ) for another $60 \mathrm{~s}$. And then the mortar was completed.

To further study the effects of NS on the hydration of cement, paste was used in this work. Paste was prepared with a $\mathrm{W} / \mathrm{B}$ ratio of 0.35 , such that $0 \%$ and $4 \%$ NS30 by weight replaced cement. The mix composition of paste is given in Table 5. The preparation of paste involved (a) weighing the components, (b) adding NS30 and SP into water, mixing them at high speed to form an aqueous suspension, and (c) pouring the solid components into water and mechanical mixing. During the mixing, the stirring blade of the paste mixer was rotation and revolution, and the paste mixer blended mixture at a constant low speed (at the rotation speed of $140 \mathrm{r} / \mathrm{min}$ and at the revolution speed of $62 \mathrm{r} / \mathrm{min}$ ) for $120 \mathrm{~s}$. Then, the paste mixer stopped stirring for $15 \mathrm{~s}$. Finally, the paste mixer blended mixture at a constant high speed (at the rotation speed of $285 \mathrm{r} / \mathrm{min}$ and at the revolution speed of $125 \mathrm{r} / \mathrm{min}$ ) for another $120 \mathrm{~s}$. And then the paste was completed.

2.3. Experimental Parameter and Methods. Apparent density was measured, according to the Standard Test Method for the performance of building mortar (JGJ/T 70-2009). Mortars were mixed by a planet-type cement sand mixing machine. Fresh mortar filled the capacity cylinder, which had a $108 \mathrm{~mm}$ inner diameter and a $109 \mathrm{~mm}$ net height. The thickness of the cylinder was $2 \mathrm{~mm}$ and its volume was $1 \mathrm{~L}$. First, the cylinder was cleaned with a damp cloth and weighed to measure the mass of the cylinder $\left(m_{1}\right)$. After artificial vibrating compaction, surplus mortars were stripped away. Finally, the weighed mass of the cylinder was $m_{2}$ and the

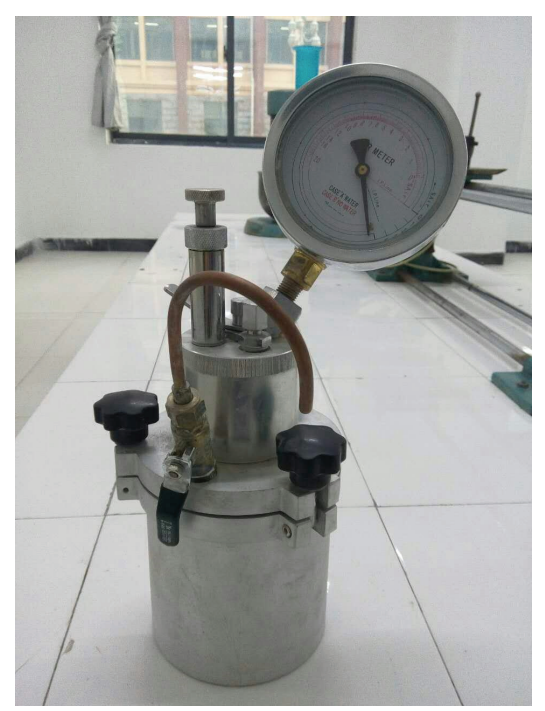

FIGURE 3: Mortar air content-measuring instrument.

first apparent density value was calculated through (1). The apparent density of the mortar is calculated as

$$
\rho=\left[\frac{\left(m_{2}-m_{1}\right)}{V}\right] \times 1000,
$$

where $\rho\left(\mathrm{kg} / \mathrm{m}^{3}\right)$ is the apparent density of the mortar, $m_{1}(\mathrm{~kg})$ is the mass of the capacity cylinder, $m_{2}(\mathrm{~kg})$ is the combined mass of the capacity cylinder and mortar, and $V(\mathrm{~L})$ is the volume of the capacity cylinder. We repeated the prior steps to test and calculate the second apparent density through formula (1). Finally, we took the average of two values as our apparent density value, accurate to $10 \mathrm{~kg} / \mathrm{m}^{3}$.

The air content was measured by the mortar air contentmeasuring instrument in Figure 3, according to the Standard Test Method for the performance of building mortar (JGJ/T 70-2009). Fresh mortar was divided into three uniform amounts that were loaded into the amount of the bowl. After artificial vibrating compaction, surplus mortars were stripped away. The mortar surface should be smooth and without bubbles. The lid was attached and then clamped to the block buttons and carried air content of the mortar. We pressed the button and read the dial when the dial was stable. We repeated the prior steps to measure the other value and we took the average of two values as the end result. If the relative error of two test values was less than $0.2 \%$, the average of two values was the final result. The test was invalid.

The setting time was measured by the concrete penetration resistance tester in Figure 4, according to the Test code for hydraulic concrete (SL 352-2006). Each setting time was tested by three samples. The test of setting time was started after mixing with water. Firstly, the mortar sample tube is placed on the penetration resistance tester. Secondly, the terminal of the pin was placed in contact with the mortar surface and the pin was vertically pressed into the mortar to a depth of $25 \mathrm{~mm}$, slowly and uniformly. The penetration resistance values and time were recorded, at $30 \mathrm{~min}$ intervals. The times of the experiment should be six at least. 
TABLE 4: Mix proportion of different cement mortars with different NS particle size.

\begin{tabular}{|c|c|c|c|c|c|c|c|}
\hline \multirow{2}{*}{ NS (wt\%) } & \multirow{2}{*}{$\mathrm{W} / \mathrm{B}$} & \multicolumn{6}{|c|}{ Mixture components } \\
\hline & & Water $(\mathrm{mL})$ & $\mathrm{P} \cdot \mathrm{O} 42.5(\mathrm{~g})$ & R.SAC42.5 (g) & Sand $(\mathrm{g})$ & NS (g) & $\mathrm{SP}(\mathrm{g})$ \\
\hline 0 & 0.35 & 87.5 & 160 & 90 & 500 & - & 5 \\
\hline 0.5 & 0.35 & 87.5 & 158.75 & 90 & 500 & 1.25 & 5 \\
\hline 1.0 & 0.35 & 87.5 & 157.5 & 90 & 500 & 2.5 & 5 \\
\hline 1.5 & 0.35 & 87.5 & 156.25 & 90 & 500 & 3.75 & 5 \\
\hline 2.0 & 0.35 & 87.5 & 155 & 90 & 500 & 5 & 5 \\
\hline 2.5 & 0.35 & 87.5 & 153.75 & 90 & 500 & 6.25 & 5 \\
\hline 3.0 & 0.35 & 87.5 & 152.5 & 90 & 500 & 7.5 & 5 \\
\hline 3.5 & 0.35 & 87.5 & 151.25 & 90 & 500 & 8.75 & 5 \\
\hline 4.0 & 0.35 & 87.5 & 150 & 90 & 500 & 10 & 5 \\
\hline 4.5 & 0.35 & 87.5 & 148.75 & 90 & 500 & 11.25 & 5 \\
\hline 5.0 & 0.35 & 87.5 & 147.5 & 90 & 500 & 12.5 & 5 \\
\hline
\end{tabular}

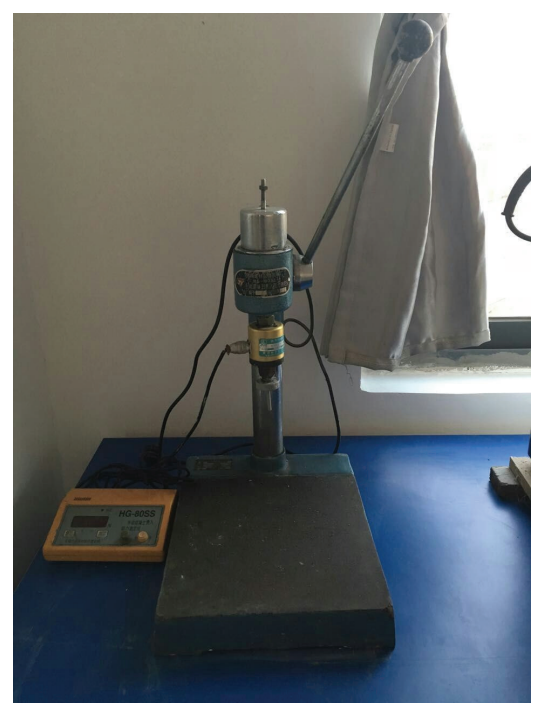

FIgURE 4: Concrete penetration resistance tester.

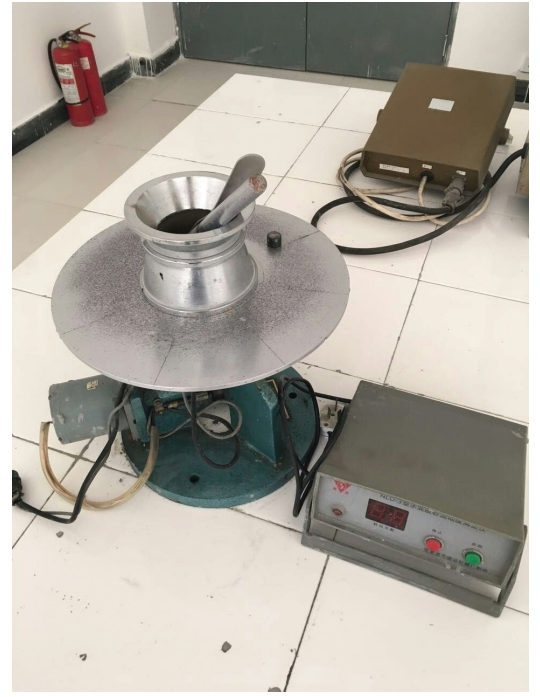

FIGURE 5: Apparatus to measure the fluidity of cement mortar.
Approaching the initial and final time, we could increase the times of the experiment. Through the experiments, we got a series of data. Taking the test time as the abscissa axis and penetration resistance values as the ordinate axis, the curves were fitted. Then, we found the initial and final time. We repeated the prior steps in every sample (3 samples per group) and calculated the average of the 3 values as our setting time. However, the maximum value of 3 values was above 1.1 times the average or the minimum value of 3 values was below 0.9 times the average and we would take the average as our final result. Otherwise, the test was invalid.

The fluidity of the mortar was tested by the apparatus of fluidity of cement mortar in Figure 5, according to the Test Method for fluidity of cement mortar (GB/T 24192005). Fresh mortar was divided into two uniforms, which were loaded into the testing model. After artificial vibrating compaction, the conical die would be vertically and slightly lifted while the instrument was operated to jump. When the instrument completed the test, we should use a steel rule to measure the two diameters, which are vertical to each other, and to calculate the average. The average should be rounding and then the integer value was the fluidity of the mortar.

\section{Results and Discussion}

3.1. Apparent Density and Air Content. The influence of NS30 content on air content and apparent density on the mortar is shown in Figure 6. The mix composition in this condition is shown in Table 4. Air content increased when the NS30 content was in the range of $0.0-2.5 \mathrm{wt} \%$. When the NS30 content was $1.0 \mathrm{wt} \%, 1.5 \mathrm{wt} \%, 2.0 \mathrm{wt} \%$, and $2.5 \mathrm{wt} \%$, the air content of mortar increased by $2.1 \%, 1.9 \%, 2.2 \%$, and $6.0 \%$, respectively, compared with the mortars without NS30. By sequentially increasing the NS30 content ( $0 \mathrm{wt} \%$, $1.0 \mathrm{wt} \%$, $1.5 \mathrm{wt} \%, 2.0 \mathrm{wt} \%$, and $2.5 \mathrm{wt} \%)$ the progression of apparent density was $-10.0 \%,-7.8 \%,-12.8 \%$, and $-14.2 \%$ compared with mortars without NS30. This reduction can be attributed to the combined effect of air-entraining and the replacement 


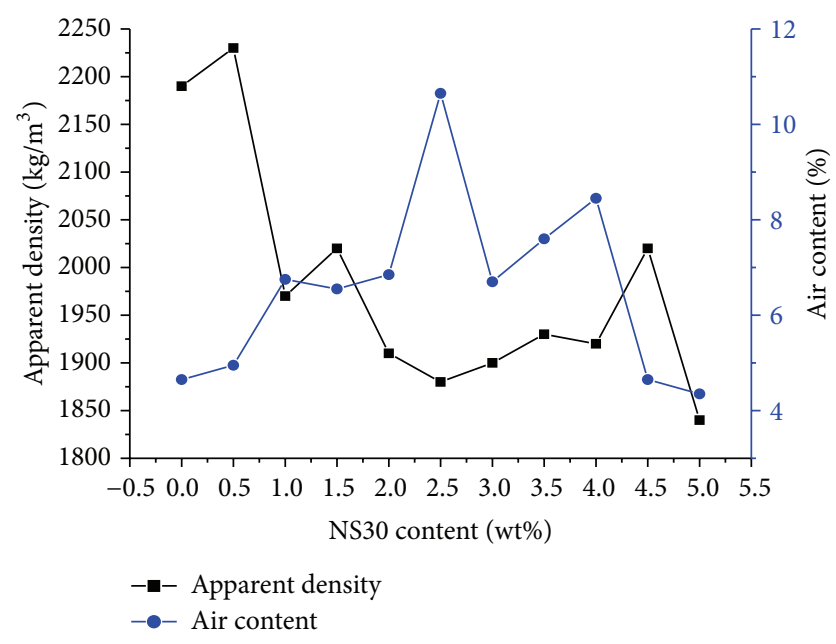

FIGURE 6: Influence of NS30 content on air content and apparent density of the mortar.

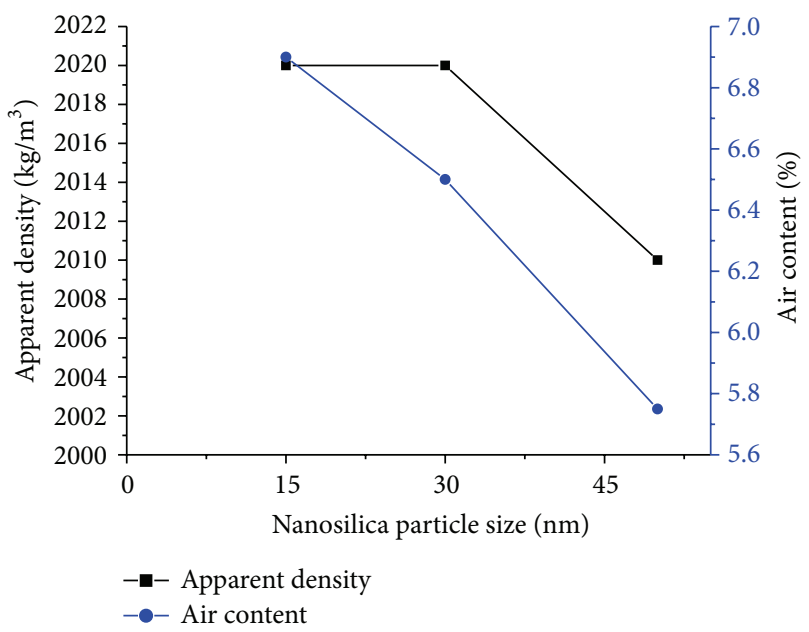

FIGURE 7: Influence of NS particle size on air content and apparent density of the mortar.

of denser cement particles by lighter NS particles. However, a less obvious regularity was observed when NS30 was incorporated into the mixture at $3.0 \mathrm{wt} \%-5.0 \mathrm{wt} \%$.

To investigate the influence of NS particle size on air content and apparent density of the mortar, three particle sizes of 15,30 , and $50 \mathrm{~nm}$ were selected. In this case, the mix composition of the mortar is shown in Table 4 with the NS content determined at $1.5 \mathrm{wt} \%$. Figure 7 presents the influence of NS particle size on air content and apparent density of the mortar. Air content of cement mortars with NS particle sizes of 30 and $50 \mathrm{~nm}$ declined by $0.4 \%$ and $1.15 \%$, respectively, compared with the mortar with NS15. However, the apparent density of the mortar decreased to $10 \mathrm{~kg} / \mathrm{m}^{3}$ when the NS particle size was $50 \mathrm{~nm}$. This trend was basically attributed to the specific surface area of the NS particle, which decreased with increased NS particle size. The effect of airentraining also declined. Given the replacement of denser

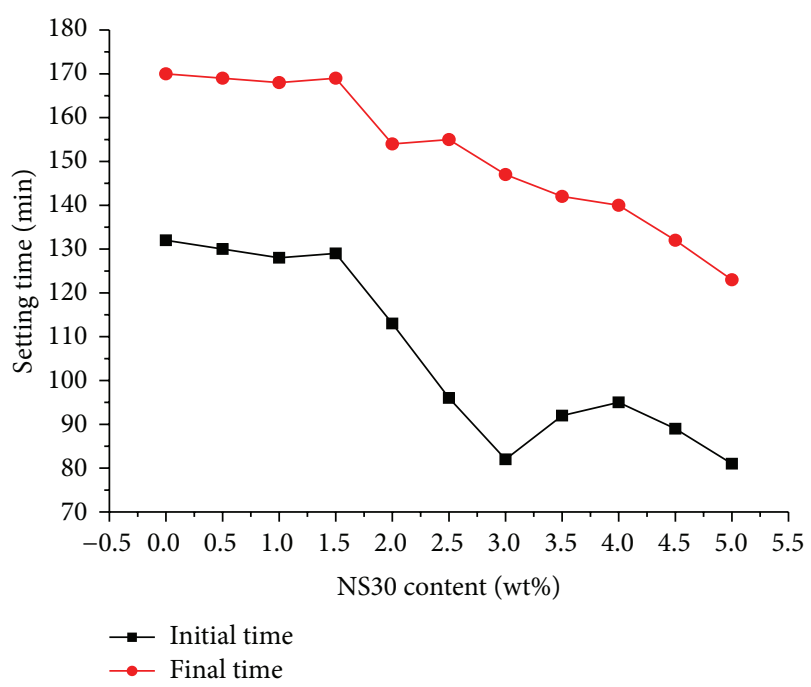

FIGURE 8: Variation in setting time (initial and final) on the mortar with the NS30 content.

cement particles by lighter NS particles, the apparent density of the mortar slightly decreased.

3.2. Setting Time. The variation in setting time of the mortar with the NS30 content is presented in Figure 8. The mix composition of the mortar is shown in Table 4. Results in Figure 8 indicated that the setting time of the mortar was slightly shortened with the NS30 content varying from $0.0 \mathrm{wt} \%$ to $1.5 \mathrm{wt} \%$, by step increments of $0.5 \mathrm{wt} \%$. With increased NS30 content from $2.0 \mathrm{wt} \%$ to $3.0 \mathrm{wt} \%$, setting time sharply decreased. With increased NS30 content from $3.5 \mathrm{wt} \%$ to $5.0 \mathrm{wt} \%$, the setting time of the mortar was slightly prolonged. With $2.0 \mathrm{wt} \% \mathrm{NS} 30$, the initial and final setting were shortened by 19 and 16 min compared with samples without NS. With $5.0 \mathrm{wt} \%$ NS30, the initial and final setting time were reduced by 51 and $47 \mathrm{~min}$, respectively, compared with the control samples (the content of NS30 is $0.0 \mathrm{wt} \%$ ). This trend was mainly related to the pozzolanic activity of NS in the continuous hydration process of cement. NS reacts with the continuous hydration of cement clinker such as $\mathrm{C}_{3} \mathrm{~S}$ and $\beta-\mathrm{C}_{2} \mathrm{~S}$, thereby producing $\mathrm{C}-\mathrm{S}-\mathrm{H}$ and $\mathrm{CH}[29,30]$. The decrease in free portlandite contents promoted further hydration of the clinker; thus, the acceleration of cement hydration shortened the curing time. The increased content of $\mathrm{C}_{4} \mathrm{~A}_{3} \overline{\mathrm{S}}$ was attributed to the portland cement mixed with the sulphoaluminate cement. The formation of ettringite and alumina gel became faster. Since the reaction of $\mathrm{CH}$ with $\mathrm{C}_{4} \mathrm{~A}_{3} \overline{\mathrm{S}}$ could produce ettringite, the content of $\mathrm{CH}$ and the alkalinity of the mortar decreased. Therefore, the hydration of $\mathrm{C}_{2} \mathrm{~S}, \mathrm{C}_{3} \mathrm{~S}$ was accelerated, which shortened the setting time. NS had a large specific surface area with a nucleating effect for hydration; it accelerated the secondary hydration reaction to increase the hydration velocity of $\mathrm{C}_{4} \mathrm{~A}_{3} \overline{\mathrm{S}}$. However, much ettringite and alumina gel may be attached onto the surface of the cement particles to prevent their further hydration. Consequently, when the NS30 content increased from $3.0 \mathrm{wt} \%$ to $5.0 \mathrm{wt} \%$, the setting time was slightly prolonged. 


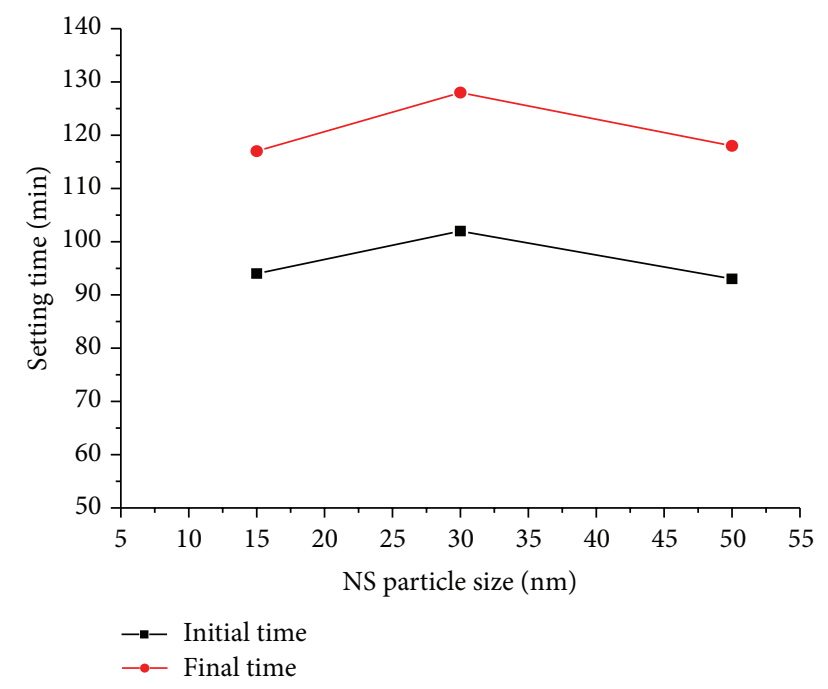

FIGURE 9: Variation in setting time (initial and final) on the mortar with the NS particle size.

The variation in setting time on the mortar with the NS particle size is shown in Figure 9. In this case, the mix composition of the mortar is shown in Table 4 with NS content $1.5 \mathrm{wt} \%$. Cement mortar with NS particle sizes of 15 and $50 \mathrm{~nm}$ had a relatively shorter setting time than the mortar with NS particle size of $30 \mathrm{~nm}$. These results showed that initial setting time was shortened by $7.8 \%$ and $8.9 \%$, whereas the final setting time was shortened by 8.6 and $8.5 \%$. As seen from Figures 8 and 9, the effect of NS content on the setting time of the cement mortar was more obvious than the effect of NS particle size on cement mortar. This trend was mainly related to weak dispersion of NS during the blending process. Thus, in the case of a high dosage NS, silica particles did not disperse well in cement matrix; this phenomenon has been studied by Khaloo et al. [31]. And due to the agglomeration of NS particles, the pozzolanic activity of NS particle was not performed very well during the hydration reaction. So the agglomeration of NS particles was found to be the main reason of the trend shown in Figure 9.

3.3. Fluidity. The influence of NS on the fluidity of the cement mortar is shown in Figure 10. Table 4 shows the mix composition of cement mortar under this condition. With $5.0 \mathrm{wt} \% \mathrm{NS} 30$, the fluidity of the cement mortar was $225 \mathrm{~mm}$, which did not meet the requirements of the code for the application of cementitious grout. However, cement mortar with NS particle sizes of 15 and $50 \mathrm{~nm}$ could meet the requirements of this code. Figure 10 presents the fluidity of cement mortar, which fluctuates between 275 and $303 \mathrm{~mm}$ after mixing NS15 and NS50. By contrast, the fluidity of the mortar decreased with increased NS30 content. While NS30 content was $5.0 \mathrm{wt} \%$, the fluidity of the mortar sharply decreased. For instance, with $4.0 \mathrm{wt} \% \mathrm{NS} 15$, the fluidity was reduced by $8.0 \%$, whereas by increasing the NS50 content to $1.0 \mathrm{wt} \%$, the fluidity decreased by $8.8 \%$ and the fluidity dropped by $25.4 \%$ with NS30 dosage at values of $5.0 \mathrm{wt} \%$. Contrasting NS30 with NS15 and NS50, the maximum value and the minimum

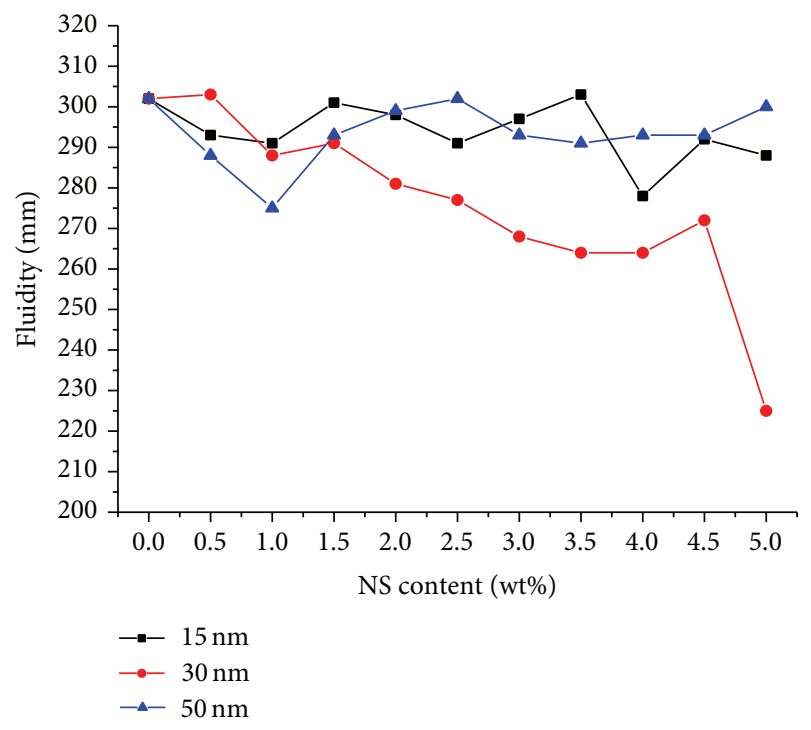

FIGURE 10: Variation in fluidity on the mortar with the NS content and NS particle size.

value of the fluidity were 225 and $303 \mathrm{~mm}$ with $0.5 \mathrm{wt} \%$ NS30 content and $5.0 \mathrm{wt} \%$ NS30 content, respectively. With the addition of NS15, the maximum value and the minimum value of the fluidity were 278 and $303 \mathrm{~mm}$ with $4.0 \mathrm{wt} \%$ NS30 content and $3.5 \mathrm{wt} \%$ NS15 content, respectively. With the increase of NS50, the maximum value and the minimum value of the fluidity were 275 and $302 \mathrm{~mm}$ with $1.0 \mathrm{wt} \%$ NS50 content and $2.5 \mathrm{wt} \% \mathrm{NS} 15$ content, respectively. With the increased content of NS, the fluidity of mortars with NS15 and NS50 was fluctuated. However, the fluidity of mortars with NS30 declined. When the content of NS30 was added up to $5.0 \mathrm{wt} \%$, the fluidity of mortars with NS30 had a sharp decrease. This trend was mainly related to the higher NS dosage and the agglomeration of NS particles.

In the mixing procedure, the NS and SP were stirred with water by the experimenter in the beaker. Therefore, this trend was mainly related to the hard to disperse NS particle during the stirring process, because the smaller the NS particle size is, the higher the surface area is; the cement was harder to mix with NS uniformly. Thus, in the case of the smaller and higher dosage NS, silica particles did not disperse well in cement matrix. The pozzolanic activity of NS particle was not performed very well during the hydration as a result of the agglomeration of NS particles. In this work, we also adopted the portland-sulphoaluminate composite system and the polycarboxylate SP. The hydrated products of calcium sulphoaluminate, $\mathrm{C}_{4} \mathrm{~A}_{3} \overline{\mathrm{S}}$, were mainly ettringite (AFt), alumina gel, calcium aluminate hydrates (AFm), and a small amount of a gelatinous substance.

However, NS particles were very small and extremely difficult to evenly disperse. Therefore, these particles often existed in the form of agglomerates in cement mortar. Furthermore, NS exhibited an extremely large specific surface area and high porosity. Hence, agglomerates can absorb a large amount of water. The effect of the mixing techniques on the properties of the mortar should be investigated. NS 
TABLE 5: Mix proportion of different pastes.

\begin{tabular}{|c|c|c|c|c|c|c|}
\hline \multirow{2}{*}{ NS30 (wt\%) } & \multirow{2}{*}{$\mathrm{W} / \mathrm{B}$} & \multicolumn{5}{|c|}{ Mixture components } \\
\hline & & Water $(\mathrm{mL})$ & $\mathrm{P} \cdot \mathrm{O} 42.5(\mathrm{~g})$ & $\mathrm{R} \cdot \mathrm{SAC} 42.5(\mathrm{~g})$ & NS30 (g) & $\mathrm{SP}(\mathrm{g})$ \\
\hline 0 & 0.35 & 87.5 & 160 & 90 & - & 5 \\
\hline 4.0 & 0.35 & 87.5 & 150 & 90 & 10 & 5 \\
\hline
\end{tabular}

was difficult to disperse, and large agglomerates cannot fill the cement particles. Less free water was replaced, and the agglomerates significantly absorbed more water. For instance, fluidity slightly decreased at a low NS30 dosage $(\leq 1.5 \%)$. Nanosilica could disperse into small agglomerates and filled the space between cement particles as filler. Consequently, more free water was replaced, and the fluidity was slowly reduced. With increased NS30 content from $2.0 \mathrm{wt} \%$ to $5.0 \mathrm{wt} \%$ accompanied by more rapid hydration, more C-S$\mathrm{H}$ gel and $\mathrm{Ca}(\mathrm{OH})_{2}$ crystals were produced. Consequently, more ettringite was obtained. Some ettringite was gained at the latter stage which filled the cement particles as fillers, but more of the ettringite covered the cement, thereby significantly increasing the absorbed water of the hydration reaction. The free water content of the slurry decreased and became insufficient to resist the flocculation of cement particles. Therefore, fluidity significantly declined.

3.4. XRD and SEM Analyses. The influence of NS on the hydration reactions and microcosmic interfaces on the mortar was studied. However, the particle size of sand was larger, thereby affecting the XRD and SEM analyses. Thus, the cement paste with NS was investigated in this work, and the mix composition of the paste is shown in Table 5. The rate of the hydration reactions of the cement became faster with the addition of NS. This finding was mainly ascribed to the chemical reactivity upon dissolution (pozzolanic activity) or to the high surface activity of NS particles, which caused the mortar to set and harden faster. The XRD analysis of hydration products of cement paste without NS and with NS30/4.0 hydrated at 1 day is illustrated in Figure 11. Moreover, the XRD curves of hydration products of cement paste without NS and NS30/4.0 hydrated at 3 days are exhibited in Figure 12. A comparison of these figures shows that the presence of AFm in the samples with NS addition could be observed after 1 day by XRD as shown in Figure 11(b). The rapid aggregation of AFm is mainly attributed to the sulphoaluminate cement. Therefore, the incorporation of NS can accelerate the hydration of sulphoaluminate cement. Note that NS**/\#\# = the content of $* * \mathrm{~nm}$ NS is \#\# in the cement-based grouting material.

To study the characteristics of the surface microstructure on the interfacial transition zone (ITZ), SEM analysis was performed in this work. The broken specimens were analyzed by SEM to study the hydration products. Figures 13 and 14 present the surface microstructure of the ITZ. The SEM analysis of cement paste without NS is shown in Figure 13(a). The ITZ of cement paste without NS has massive crystals of $\mathrm{AFt}$ and $\mathrm{Ca}(\mathrm{OH})_{2}$. These effects can be explained by internal bleeding caused by the high local $\mathrm{W} / \mathrm{B}$ ratio at the ITZ,

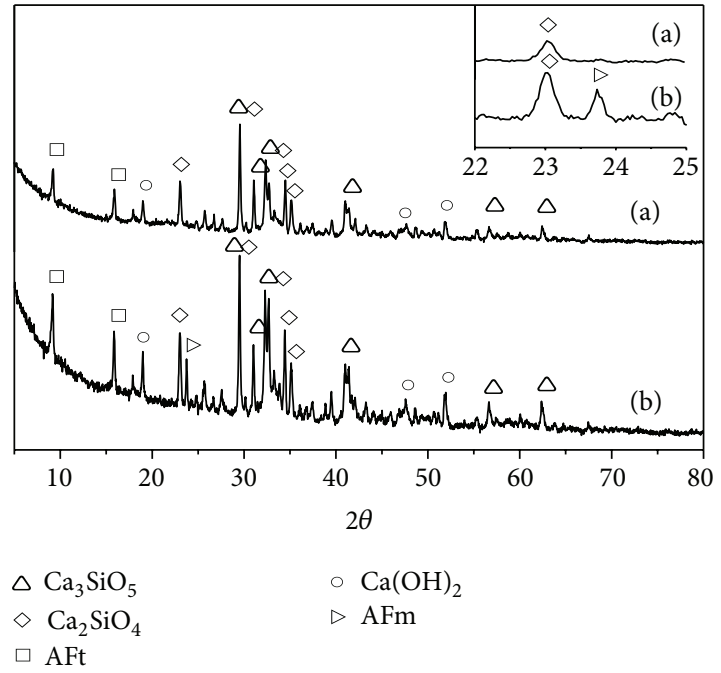

FIGURE 11: XRD of cement paste (a) without NS and (b) with NS30/4.0 at 1 day.

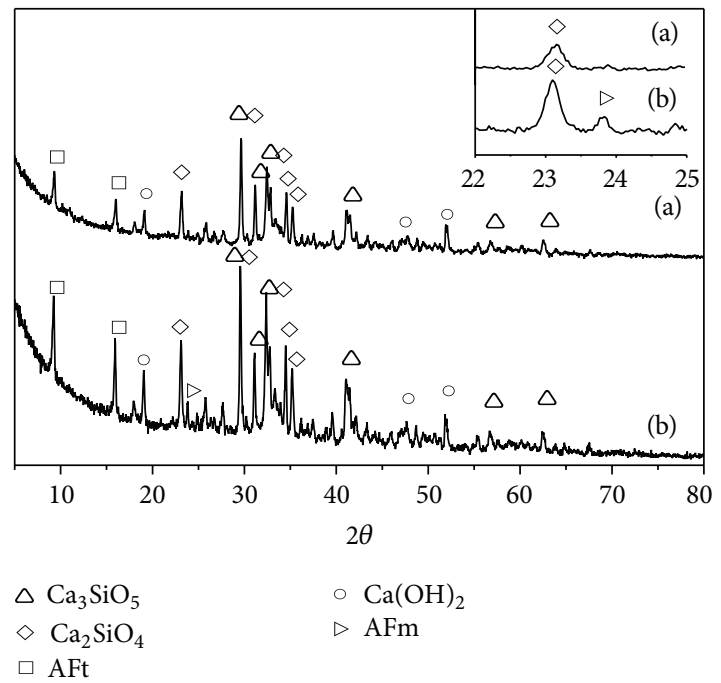

FIGURE 12: XRD of cement paste (a) without NS and (b) with NS30/4.0 at 3 days.

which produces large crystals and porous structures in plain samples.

Figure 13(b) shows the image of cement paste with NS30/4.0 at 1 day. Compared with Figures 13(a) and 13(b), the sample with NS30/4.0 had denser ITZ than the control sample. The ITZ with NS30/4.0 was denser because NS particles can fill the space between cement grains, a phenomenon called the packing effect of NS. Massive $\mathrm{Ca}(\mathrm{OH})_{2}$ crystals 


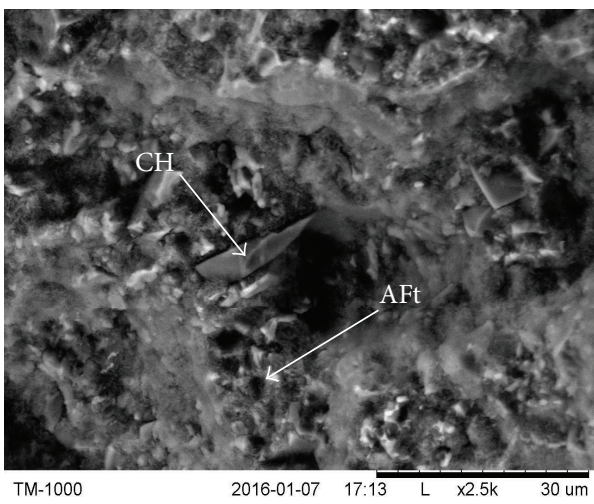

(a)

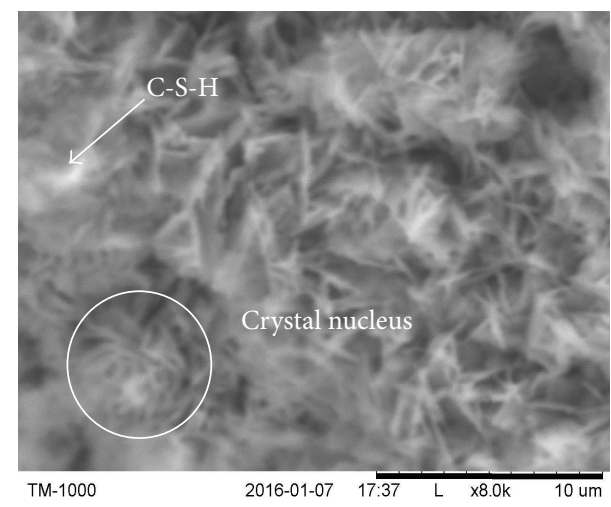

(b)

FIGURE 13: SEM of cement paste (a) without NS and (b) with NS30/4.0 at 1 day.

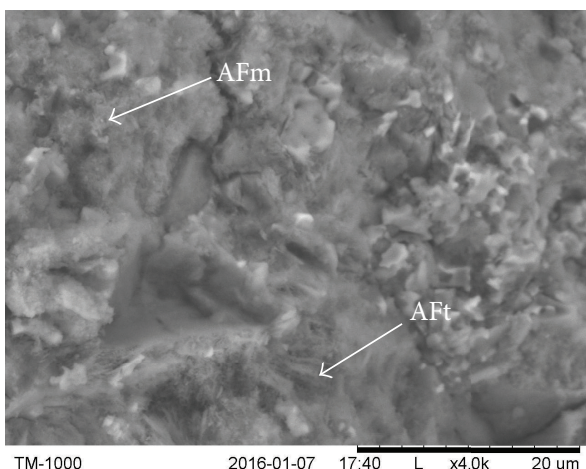

(a)

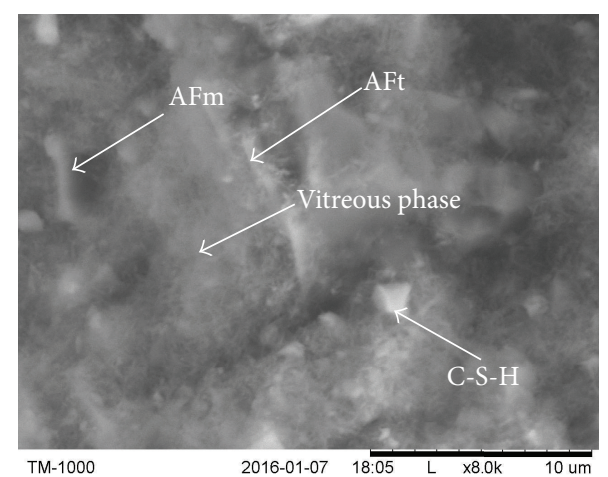

(b)

Figure 14: SEM of cement paste (a) without NS and (b) with NS30/4.0 at 3 days.

can react with NS to form the denser C-S-H gel. Nanosilica particles filled the gap between the cement particles as the packing effects of NS, making the particle size distribution of the cementitious material reach the state of dense packing. In addition, NSs could fill in the pores of the grouting material and provided the attachment point of the nucleus for hydrated products of C-S-H because of the small particle size, large specific surface area, and high surface activity. The network of C-S-H was continuously generated and developed outward until the surfaces of different crystal nuclei are close to one another. The C-S-H gel on the surface intertwined and formed a stable network skeleton. As the reaction continued, cement particles were surrounded by the accumulating hydration products, namely, AFt, AFm, and the $\mathrm{C}-\mathrm{S}-\mathrm{H}$ gel. This behavior could contribute to the microscopic and submicroscopic structure of the grouting material.

The differences in the surface microstructure of cement paste without NS and with NS30/4.0 at 3 days are shown in Figures 14(a) and 14(b). AFt and AFm crystals were observed in Figure 14(a). This behavior was related to the poor dispersion of the cement grains near the ITZ. With the addition of NS, the packing effects of NS can not only fill the capillary pores effectively but also reduce the gap at the joint of the aggregate interface, making the ITZ not obvious. This case tended to accumulate water and other ionic species in the ITZ, thereby promoting the stability of these crystalline chemical structures. Cement paste with NS30/4.0 showed the aggregation of AFm and Aft, as well as the appearance of a vitreous phase. The latter was attributed to the pozzolanic reaction, which made the ITZ denser. Notably, the improvements can be related to other aspects, such as durability or even tensile strength $[1,31]$.

\section{Conclusions}

The abovementioned findings led to the following conclusions:

(1) With increased NS content, air content increased and apparent density decreased, but the NS particle sizes had minimal effect on the air content and apparent density.

(2) With increased NS content, the setting time of mortar was significantly shortened; however, NS particle sizes had little influence on the setting time.

(3) The effect of fluidity on the mortars adding NS with particle size of $30 \mathrm{~nm}$ was larger than NS with particle 
sizes of 15 and $50 \mathrm{~nm}$ and the fluidity decreased with increased NS content, but the fluidity of mortars with the particle sizes of 15 and $50 \mathrm{~nm}$ was almost not affected by the NS content.

(4) The formation of ettringite was promoted and the process of hydration reaction of cement was accelerated with the addition of NS.

(5) With the addition of NS, the formation of C-S-H gel was promoted and the surface morphology of mortar was improved, making the interfacial transition zone denser.

\section{Competing Interests}

The authors declare that they have no competing interests.

\section{Acknowledgments}

The authors are grateful for the financial support from the National Natural Science Foundation of China (51208471), Outstanding Young Talent Research Fund of Zhengzhou University (1421322059), Science and Technology Planning project of Transportation in Henan Province (2016Y2-2), and the Specialized Research Foundation for the Doctoral Program of Higher Education (20114101120008).

\section{References}

[1] L. Senff, J. A. Labrincha, V. M. Ferreira, D. Hotza, and W. L. Repette, "Effect of nano-silica on rheology and fresh properties of cement pastes and mortars," Construction and Building Materials, vol. 23, no. 7, pp. 2487-2491, 2009.

[2] H. Li, H.-G. Xiao, J. Yuan, and J. Ou, "Microstructure of cement mortar with nano-particles," Composites Part B: Engineering, vol. 35, no. 2, pp. 185-189, 2004.

[3] I. Older, Lea's Chemistry of Cement and Concrete, Arnold, London, UK, 4th edition, 1998.

[4] A. M. Neville, Properties of Concrete, ELBS with Addison Wesley Longman, Essex, UK, 4th edition, 1996.

[5] M. Sonebi, E. García-Taengua, K. M. A. Hossain, J. Khatib, and M. Lachemi, "Effect of nanosilica addition on the fresh properties and shrinkage of mortars with fly ash and superplasticizer," Construction and Building Materials, vol. 84, article no. 6400, pp. 269-276, 2015.

[6] S. Collepardi, A. Borsoi, J. J. Ogoumah Olagot et al., "Influence of nano-sized mineral additions on performance of SCC," in Proceedings of the 6th International Congress, Global Construction, Ultimate Concrete Opportunities, Dundee, UK, July 2005.

[7] J. Björnström, A. Martinelli, A. Matic, L. Börjesson, and I. Panas, "Accelerating effects of colloidal nano-silica for beneficial calcium-silicate-hydrate formation in cement," Chemical Physics Letters, vol. 392, no. 1-3, pp. 242-248, 2004.

[8] Y. Qing, Z. Zenan, K. Deyu, and C. Rongshen, "Influence of nano- $\mathrm{SiO}_{2}$ addition on properties of hardened cement paste as compared with silica fume," Construction and Building Materials, vol. 21, no. 3, pp. 539-545, 2007.
[9] M. Collepardi, J. J. Ogoumah Olagot, U. Skarp et al., "Influence of amorphous colloidal silica on the properties of selfcompacting concretes," in Proceedings of the International Conference in Concrete Constructions-Innovations and Developments in Concrete Materials and Constructions, pp. 473-483, Dundee, Scotland, September 2002.

[10] H. Li, M.-H. Zhang, and J.-P. Ou, "Abrasion resistance of concrete containing nano-particles for pavement," Wear, vol. 260, no. 11-12, pp. 1262-1266, 2006.

[11] B.-W. Jo, C.-H. Kim, G.-H. Tae, and J.-B. Park, "Characteristics of cement mortar with nano- $\mathrm{SiO}_{2}$ particles," Construction and Building Materials, vol. 21, no. 6, pp. 1351-1355, 2007.

[12] G. Li, "Properties of high-volume fly ash concrete incorporating nano- $\mathrm{SiO}_{2}$," Cement \& Concrete Research, vol. 34, no. 6, pp. 1043-1049, 2004.

[13] J.-Y. Shih, T.-P. Chang, and T.-C. Hsiao, "Effect of nanosilica on characterization of Portland cement composite," Materials Science and Engineering: A, vol. 424, no. 1-2, pp. 266-274, 2006.

[14] A. Nazari and S. Riahi, "The role of $\mathrm{SiO}_{2}$ nanoparticles and ground granulated blast furnace slag admixtures on physical, thermal and mechanical properties of self compacting concrete," Materials Science and Engineering A, vol. 528, no. 4-5, pp. 2149-2157, 2011.

[15] M.-H. Zhang and J. Islam, "Use of nano-silica to reduce setting time and increase early strength of concretes with high volumes of fly ash or slag," Construction and Building Materials, vol. 29, pp. 573-580, 2012.

[16] R. M. Martins and A. J. F. Bombard, "Rheology of fresh cement paste with superplasticizer and nanosilica admixtures studied by response surface methodology," Materials and Structures, vol. 45, no. 6, pp. 905-921, 2012.

[17] A. Nazari and S. Riahi, "Microstructural, thermal, physical and mechanical behavior of the self compacting concrete containing $\mathrm{SiO}_{2}$ nanoparticles," Materials Science and Engineering: $A$, vol. 527, no. 29-30, pp. 7663-7672, 2010.

[18] M. Stefanidou and I. Papayianni, "Influence of nano- $\mathrm{SiO}_{2}$ on the Portland cement pastes," Composites Part B: Engineering, vol. 43, no. 6, pp. 2706-2710, 2012.

[19] M. Choolaei, A. M. Rashidi, M. Ardjmand, A. Yadegari, and H. Soltanian, "The effect of nanosilica on the physical properties of oil well cement," Materials Science and Engineering A, vol. 538, pp. 288-294, 2012.

[20] V. A. Doroganov, "Aspects of the modification of refractory concrete with nanosilica," Refractories and Industrial Ceramics, vol. 52, no. 6, pp. 409-413, 2012.

[21] F. Sanchez and K. Sobolev, "Nanotechnology in concrete-a review," Construction and Building Materials, vol. 24, no. 11, pp. 2060-2071, 2010.

[22] A. T. DiBenedetto, "Tailoring of interfaces in glass fiber reinforced polymer composites: a review," Materials Science and Engineering: A, vol. 302, no. 1, pp. 74-82, 2001.

[23] J. M. Fraile, J. I. García, J. A. Mayoral, and E. Vispe, "Comparison of hydrophilic and hydrophobic silicas as supports for titanium catalysts," Applied Catalysis A: General, vol. 276, no. 1-2, pp. 113122, 2004.

[24] F. Bauer, H.-J. Gläsel, E. Hartmann, H. Langguth, and R. Hinterwaldner, "Functionalized inorganic/organic nanocomposites as new basic raw materials for adhesives and sealants," International Journal of Adhesion and Adhesives, vol. 24, no. 6, pp. 519-522, 2004. 
[25] O. M. Al-Azzawi, C. M. Hofmann, G. A. Baker, and S. N. Baker, "Nanosilica-supported polyethoxyamines as low-cost, reversible carbon dioxide sorbents," Journal of Colloid and Interface Science, vol. 385, no. 1, pp. 154-159, 2012.

[26] S. Rajendran, V. S. Bama, and M. R. Prabhu, "Effect of lithium salt concentration in PVAc/PMMA-based gel polymer electrolytes," Ionics, vol. 16, no. 1, pp. 27-32, 2010.

[27] A. Dorigato, M. Sebastiani, A. Pegoretti, and L. Fambri, "Effect of silica nanoparticles on the mechanical performances of poly(lactic acid)," Journal of Polymers and the Environment, vol. 20, no. 3, pp. 713-725, 2012.

[28] I. A. Rahman and V. Padavettan, "Synthesis of silica nanoparticles by sol-gel: size-dependent properties, surface modification, and applications in silica-polymer nanocomposites-a review," Journal of Nanomaterials, vol. 2012, Article ID 132424, 15 pages, 2012.

[29] X. Xu and Z. Lu, "Effect of nano-silicon dioxide on hydration and hardening of portland cement," Journal of the Chinese Ceramic Society, vol. 35, no. 4, pp. 478-484, 2007.

[30] Q. Lin, X. H. Lan, Y. B. Li et al., "Preparation and characterization of novel alkali-activated nano silica cements for biomedical application," Journal of Biomedical Materials Research Part B: Applied Biomaterials, vol. 95, no. 2, pp. 347-356, 2010.

[31] A. R. Khaloo, A. G. Vayghan, and M. Bolhassani, "Mechanical and microstructural properties of cement paste incorporating nano silica particles with various specific surface areas," Key Engineering Materials, no. 478, pp. 19-24, 2011. 

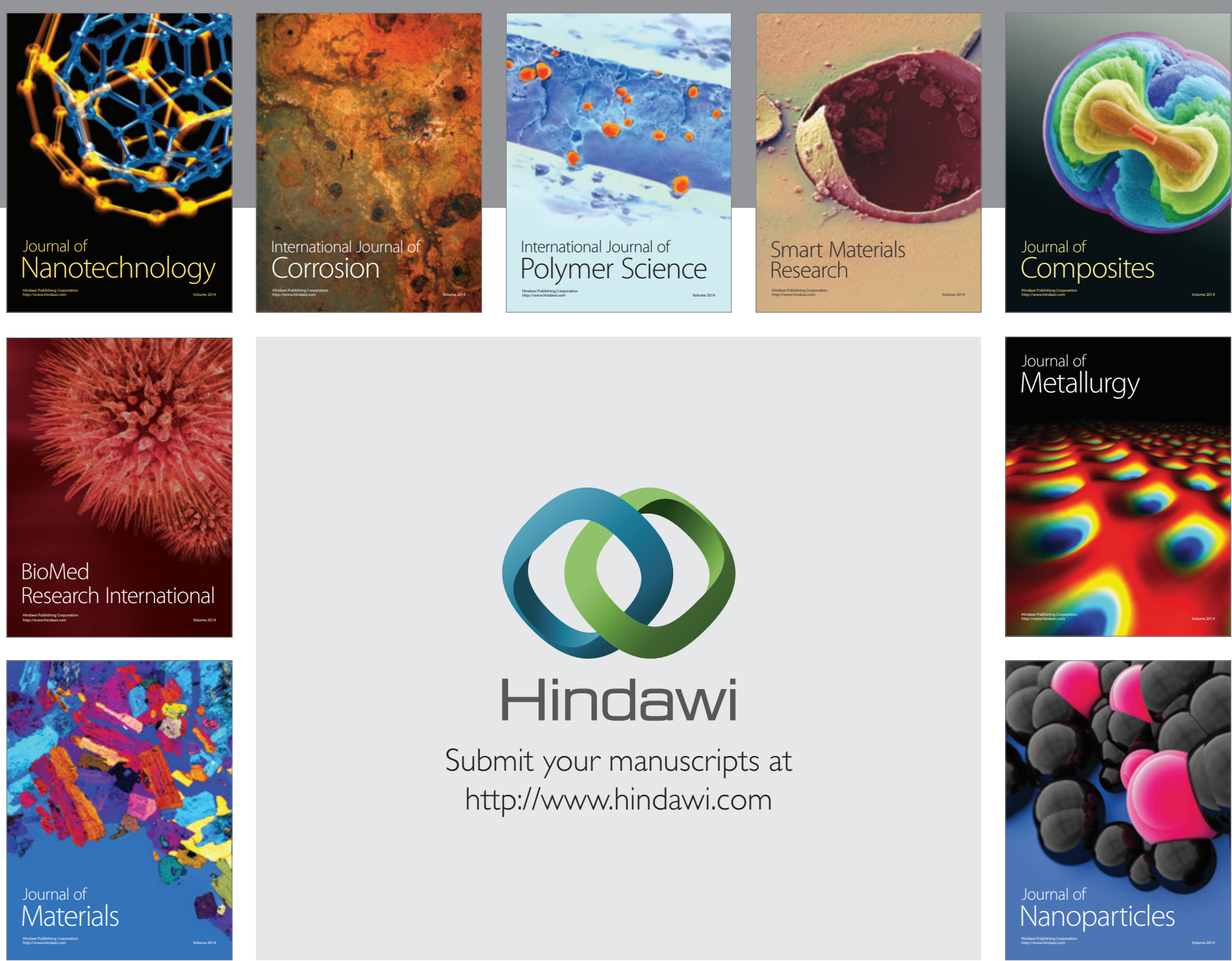

\section{Hindawi}

Submit your manuscripts at

http://www.hindawi.com

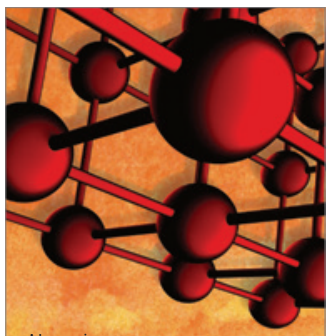

Materials Science and Engineering
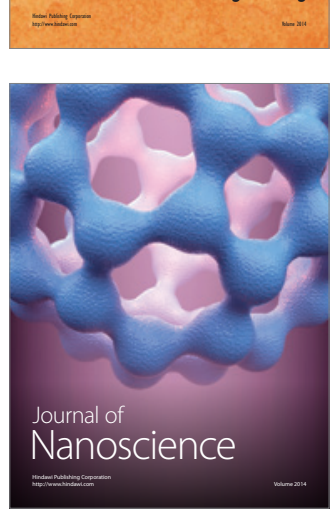
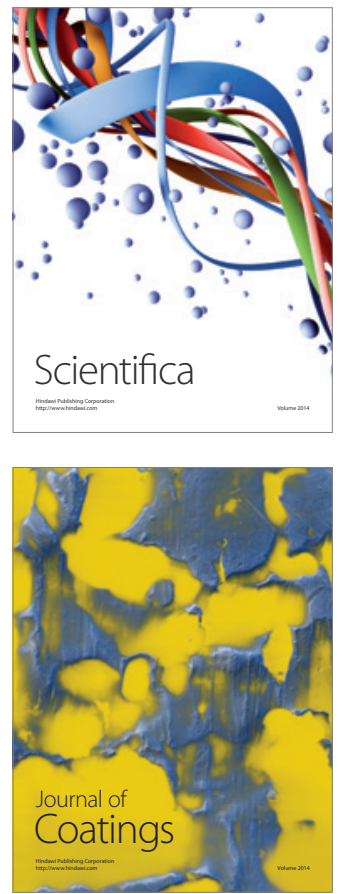
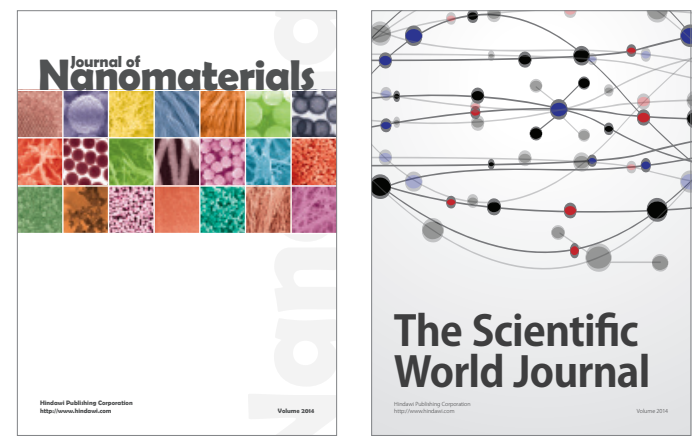

The Scientific World Journal
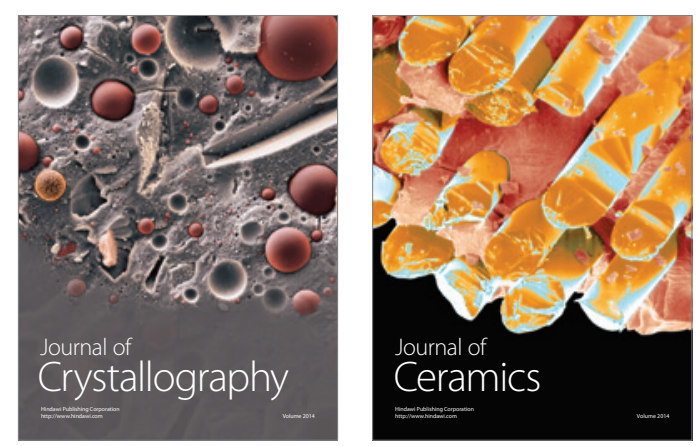
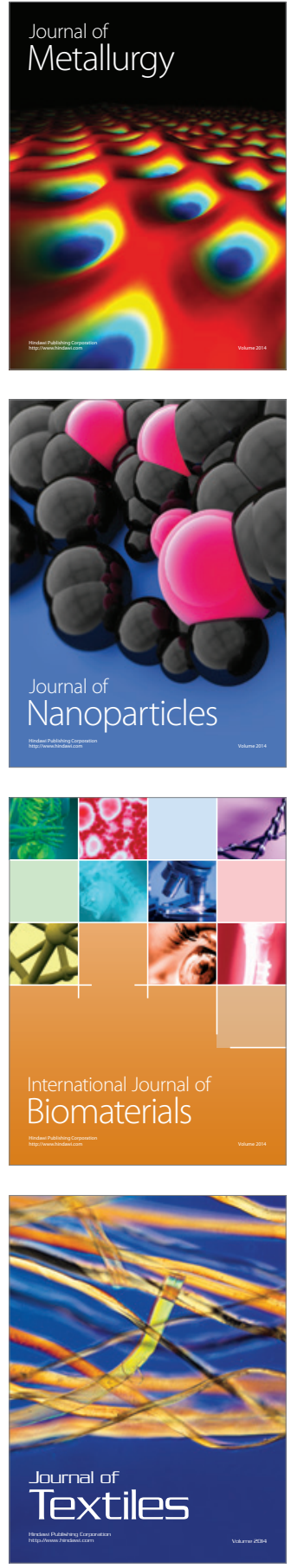